\title{
Influence of the wall on the droplet evaporation
}

\author{
S. Y. Misyura ${ }^{1 \mathrm{a}}$, V. S. Morozov ${ }^{1}$ \\ ${ }^{1}$ Institute of Thermophysics Siberian Branch, Russian Academy of Sciences, Lavrentiev Ave. 1, Novosibirsk, \\ 630090, Russia
}

\begin{abstract}
Evaporative influence of the wall material and its thickness has been investigated in the present study. The wall influence for heat exchangers is particularly important in the boiling transition regime and in the event of the Leidenfrost temperature. The experimental points significantly diverge in the transition area of the boiling crisis. This fact can be explained by a different residence time of droplet on the wall surface. The discrepancy between the experimental data also takes place at the Leidenfrost temperature. The lower the thermal diffusivity of the wall material (high thermal inertia), the more the wall is cooled under a droplet.
\end{abstract}

\section{Introduction}

The efficiency of the energy apparatus is dependent on the intensity of heat and mass transfer. The wall influence for heat exchangers is particularly important in the boiling transition regime and in the event of the Leidenfrost temperature. Nonstationary droplet boiling with a high superheat depends on the geometric and physical-chemical properties of the wall. The rapid droplet evaporation essentially depends on the properties of the wall. Evaporation features of liquid batches have been studied [1-16]. Evaporative influence of the wall material and its thickness has been investigated in the present study.

\section{Experimental data}

Description of the experimental setup is presented in [2] (ambient temperature was $23{ }^{\circ} \mathrm{C}, 1 \mathrm{~atm}$., the wall temperature was kept constant to within $1{ }^{\circ} \mathrm{C}$, a droplet placed on the horizontal wall with the help of microdispensers). The wall influence for heat exchangers is particularly important in the boiling transition regime (periodic separation of the liquid from the wall) and in the event of the Leidenfrost temperature (formation of a stable steam layer). Fig. 1 shows the total time of evaporation of distilled water $\left(V_{0}=0.046 \mathrm{~cm}^{3}\right)$ depending on the wall temperature by using different materials of the working section. Work sections have the same wall thickness of $30 \mathrm{~mm}$ and the same class of 10 roughness. The experimental points significantly diverge in the transition area of the boiling crisis. This fact can be explained by a different residence time of droplet on the wall surface (vapor heat

\section{${ }^{a}$ Corresponding author: misyura@itp.nsc.ru}


transfer is much lower than the liquid heat transfer). The discrepancy between the experimental data also takes place at the Leidenfrost temperature. The lower the thermal diffusivity of the wall material (high thermal inertia), the more the wall is cooled under a droplet. As can be seen from the graphs, the thermal diffusivity changes boiling crisis start and the length of the transition crisis. Fig. 2 shows the total time of evaporation of distilled water for various works. The initial droplet volume for all the curves was similar. A significant delay for the boiling crisis [15] probably due to the formation of the oxide film. The thermal conductivity of the oxide film is much lower copper. Type of the evaporation curve depends on the thermal diffusivity of the wall material, its thickness and roughness.

Thus, there is a delay for the boiling crisis toward higher temperatures and heat fluxes in the application of materials with low thermal conductivity, thin wall and the oxidized surface.

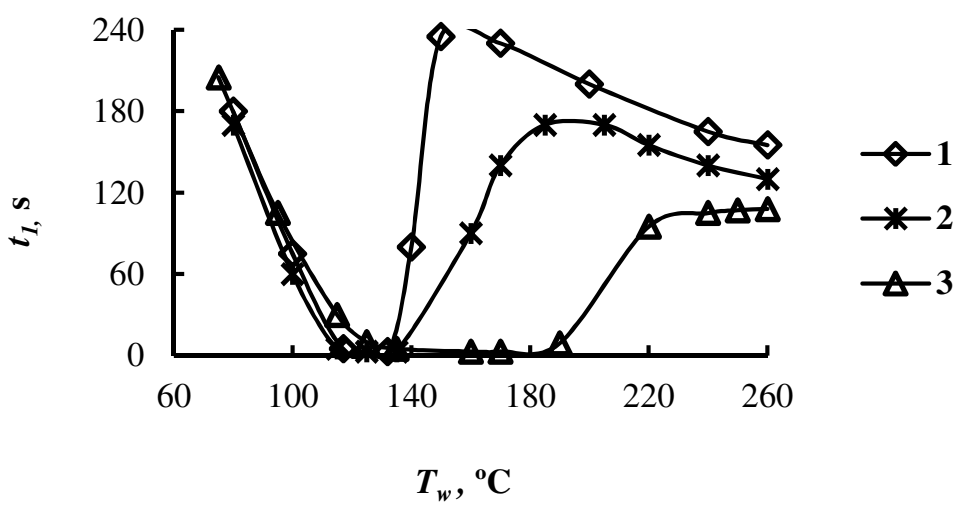

Figure 1. The dependence of the total evaporation time $\left(t_{1}\right)$ for distilled water drops on the wall temperature $\left(V_{0}=\right.$ $0.046 \mathrm{~cm}^{3}$ ) for different wall materials: Curve 1 - copper (M1), Curve 2 - aluminum alloy (D16), Curve 3 stainless steel.

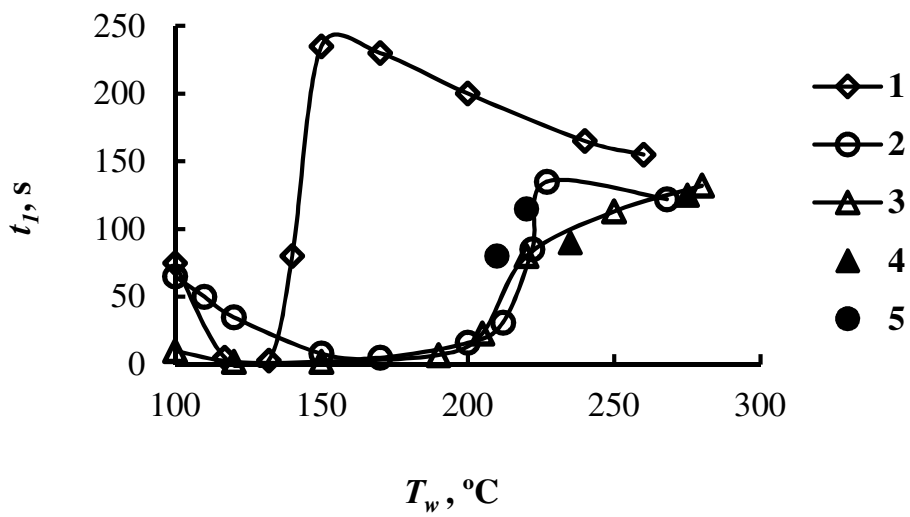

Figure 2. Dependence of the total evaporation time of distilled water from the wall temperature: curve $1-V_{0}=$ $0.046 \mathrm{~cm}^{3}$ (copper M1, the wall thickness of $30 \mathrm{~mm}$, the surface roughness of the class 10; Curve $2-0.0465 \mathrm{~cm}^{3}$, brass, $2 \mathrm{~mm}$, grade 7 [16]; Curve $3-0.051 \mathrm{~cm}^{3}$, copper [15]; $4-0.046 \mathrm{~cm}^{3}$ copper, $30 \mathrm{~mm}$, the oxidized surface; $5-0.046 \mathrm{~cm}^{3}$, brass, $2 \mathrm{~mm}$, grade 7 .

\section{Acknowledgements}

This work was supported by grants of Russian Science Foundation (Project № 15-19-10025). 


\section{References}

[1] V.E. Nakoryakov, S.Ya Misyura, S.L Elistratov, R.A. Dekhtyar, J. Engineering Thermophysics 23 (4) 257 (2014).

[2] V.E. Nakoryakov, S.Y. Misyura, S.L. Elistratov, J. Engineering Thermophysics 20 (4) 1-6 (2011).

[3] B.P. Avksentyuk, V.V. Ovchinnikov, Thermophys. and Aeromech 11 (4) 609-616 (2004).

[4] M.V. Bartashevich, O.A. Kabov, V.V. Kuznetsov, Fluid Dynamics 45 (6) 924-929 (2010).

[5] E.S. Chachilo, M.N. Grehov, D.V. Feoktistov, MATEC Web of Conferences 19 1-7 (2014).

[6] D.V. Feoktistov, G.V. Kuznetsov, E.G. Orlova, EPJ Web of Conferences $76 \quad 012039$ 1-8 (2014).

[7] D.V. Feoktistov, K.A. Batischeva, E.G. Orlova, MATEC Web of Conferences 1901001 1-4 (2014).

[8] D.V. Feoktistov, I.A. Afanasyev, E.G. Orlova, EPJ Web of Conferences 8201054 1-5 (2015).

[9] V.E. Nakoryakov, S.Y. Misyura, Doklady Physics 59 (10) 441-445 (2014).

[10] V.E. Nakoryakov, S.Y. Misyura, S.L. Elistratov, J. Engineering Thermophysics 22 (1) 1-7 (2013).

[11] S.Ya. Misyura, Int. J. Heat Mass Transfer 71 197-205 (2014).

[12] D.V. Feoktistov, K.A. Batischeva, E.G. Orlova, EPJ Web of Conferences 8201055 1-4 (2015).

[13] S.Ya. Misyura, Int. J. Thermal Sciences 92 34-43 (2015).

[14] A.N. Pavlenko, A.A. Tairov, V.E. Zhukov, A.A. Levin, A.N. Tsoi, J. Engineering Thermophysics 20 (4) 1-27 (2011).

[15] E.V. Anokhina, Technical Physics 55 (8) 1107-1112 (2010).

[16] V.M. Borishansky, Heat transfer to liquid free spreading from the surface heated above the boiling temperature, In Coll. "The Questions of Heat Transfer at a Change in the Aggregate State of the Substance”, edit. by S.S. Kutateladze. Moscow: Sate Energy Publisher, P. 118-155 (1953). 